\title{
The Use of Home Noninvasive Ventilation in Chronic Hypercapnic Chronic Obstructive Pulmonary Disease
}

\author{
Michael R. Jacobs, PharmD and Gerard J. Criner, MD
}

Temple Lung Center, Temple University School of Medicine, Philadelphia, USA

\section{ABSTRACT}

The primary objective of this review is to assess the role of noninvasive ventilation in the management of chronic obstructive pulmonary disease (COPD) patients with clinically stable hypercapnic respiratory failure. Noninvasive ventilation can be provided by either negative-pressure or positive-pressure devices. Of the two methods, positive-pressure devices are more commonly employed and are the focus of this review. The use of noninvasive positive-pressure ventilation is widely accepted for the management of hypercapnic respiratory failure in hospitalized COPD patients during exacerbations. However, the value of chronic home noninvasive positive-pressure ventilation for hypercapnic respiratory failure in stable patients with COPD is unresolved. Questions remain regarding the selection of patients most likely to benefit from home noninvasive positive-pressure ventilation for stable COPD, the inspiratory pressures that should be administered, and how to maximize patient compliance. We review the available evidence to help elucidate what is known and what remains to be determined regarding the use of chronic home noninvasive positive-pressure ventilation in these patients. (BRN Rev. 2016;2:98-113) Corresponding author: Michael R. Jacobs, Michael.Jacobs@tuhs.temple.edu

Key words: COPD. Noninvasive positive pressure ventilation. Outpatient therapy. 


\section{INTRODUCTION}

Noninvasive ventilation in the form of noninvasive positive-pressure ventilation (NPPV) has become the standard of care for decreasing the morbidity and mortality of patients who are hospitalized with an exacerbation of chronic obstructive pulmonary disease (COPD) and acute respiratory failure ${ }^{1-3}$. However, whether to use NPPV chronically at home to treat patients with acute-on-chronic respiratory failure following hospitalization remains an important clinical question. Two recent retrospective studies show reductions in re-hospitalization and improved survival with using NPPV post-hospitalization, while others have demonstrated no improvement ${ }^{4,5}$. However, two recent prospective randomized controlled trials have yielded conflicting data on the use of home NPPV on survival and re-hospitalization in chronic hypercapnic COPD ${ }^{6,7}$. Several factors may account for these discrepancies: differences in patient selection and poorly characterized patient populations and underpowered studies; NPPV settings incapable of achieving adequate ventilation; and poor patient adherence with NPPV treatment. Because of these limited and conflicting data, NPPV is currently considered as standard treatment for acute respiratory failure in hospitalized COPD patients; the use of home NPPV post-discharge to prevent recurrent respiratory failure and re-hospitalization is not recommended ${ }^{8}$.

In this article we review the pathophysiology of hypercapnic respiratory failure and methods for delivering NPPV, and define those patients with COPD who may be candidates for the intervention, and describe the outcomes that can reasonably be expected based on currently available evidence.

\section{PATHOPHYSIOLOGY OF HYPERCAPNIC RESPIRATORY FAILURE IN COPD}

Knowledge of the pathophysiology of hypercapnic respiratory failure in COPD is essential for the appropriate selection and use of respiratory assistance devices. Generally, increased arterial carbon dioxide partial pressure $\left(\mathrm{PaCO}_{2}\right)$ or hypercapnia can be produced by either an increase in carbon dioxide production, as may be seen in severe burns or sepsis, or by a reduction in alveolar ventilation? Reduction in alveolar ventilation is the primary process responsible for hypercapnia in COPD. Alveolar ventilation is reduced by chronic inflammation of the small airways, resulting in airway wall thickening, mucous hypersecretion, and a narrowing of the airway lumen. In patients with emphysema, alveolar destruction not only reduces the surface area available for gas exchange, but also leads to a loss of pulmonary capillaries and subsequent ventilation-perfusion mismatching. Hypercapnia is also worsened by increases in inspiratory and expiratory airway resistance, and dynamic hyperinflation. Compared with those without COPD, inspiratory pressures are higher in patients with stable COPD and can more than double during an acute exacerbation due to the presence of mucus as well as airway inflammation and oede$\mathrm{ma}^{10-12}$. Airway resistance is increased during expiration in patients with COPD due to an increase in airways obstruction from inflammation and oedema, and in those with emphysema, decreased lung recoil can lead to airway collapse due to a loss of airways tethering $^{13}$. As a consequence, pressures at the alveolar level are elevated at the end of expiration. This has been called intrinsic positive-end 
expiratory pressure (PEEPi) or auto-PEEP14. Because the pressure in the alveoli cannot be lowered to the ambient pressure, alveolar gas remains trapped, resulting in static hyperinflation of the lung. Physical activity, or tachypnoea, produced by an exacerbation of COPD worsens gas trapping because there is insufficient time for the air in the alveoli to be expired before the next inspiration (dynamic hyperinflation $)^{15}$. While the factors mentioned above largely explain the development of hypercapnic respiratory failure, disorders of respiratory muscle structure and function have also been shown to play an important, albeit less well understood role. The inability of many COPD patients to generate normal inspiratory pressures has been interpreted in the past as diaphragmatic fatigue ${ }^{16}$. More recently it has been shown that diaphragm strength and endurance in patients with COPD may actually exceed that of individuals without $\mathrm{COPD}^{17}$. It is now known that complex interactions involving the shape of the chest wall, diaphragm muscle fibre length and composition, and various aspects of cellular metabolism affect respiratory muscle function. A discussion of these factors is beyond the scope of this review and the reader is directed to several excellent publications of this topic ${ }^{16-18}$.

Noninvasive positive-pressure ventilation produces a number of beneficial effects that ultimately lead to improved gas exchange, which is reflected in increased oxygen partial pressure $\left(\mathrm{PaO}_{2}\right)$ and decreased $\mathrm{PaCO}_{2}$ even though no changes were seen in alveolar ventilation as measured by multiple inert gas elimination technique. Increases are seen in both lung volume and tidal volume that contribute to improved oxygenation ${ }^{19}$. The positive intrathoracic pressure produced by NPPV affects the left and right ventricles differently. Venous return to the right ventricle is reduced, thus reducing cardiac output to the lungs, which in and of itself seems to be detrimental. However, at the same time, left ventricular afterload is reduced with a subsequent increase in left ventricular output ${ }^{20}$. The negative effect on the right ventricle is more than offset by the positive effect on the left ventricle, with the net effect of NPPV to reduce or even reverse pulmonary oedema. Finally, although the role of respiratory muscle fatigue in the development of hypercapnic respiratory failure remains uncertain, it is clear that dyspnoea and the work of breathing is reduced by NPPV.

\section{CHOICES FOR NONINVASIVE VENTILATION}

Noninvasive ventilation can be provided by two basic means: negative pressure generators and positive pressure generators. Negative-pressure ventilators provide ventilator support by encasing the thorax in whole-body tanks, a cuirass shell, or a poncho-style wrap. The principle is to use the chest wall and diaphragm as a set of bellows; the ventilator creates a sub-atmospheric pressure, acting like a vacuum, pulling the chest wall up and out and the diaphragm down ${ }^{21}$. This results in negative intrathoracic pressure and creates a pressure gradient for flow of air in through the upper airway or tracheostomy. Exhalation occurs by passive recoil of the chest wall. One drawback is that the negative pressure can lead to upper airway obstruction with reduced airflow and desaturation. Because of the limited use of negative pressure ventilation in the domiciliary management of hypercapnic COPD, it will not be discussed further in this review. 
Noninvasive positive-pressure ventilation delivered through a mask has become the predominant method of providing noninvasive ventilator support. This method avoids the problems of upper airway obstruction, is more comfortable, allows the patient to move body position more easily, and is easier for the patient to turn on and off. Ventilator support can be achieved through a variety of facemask interfaces and ventilator modes. Older models of noninvasive ventilators required oxygen to be bled into the system, but current models incorporate oxygen blenders for precise delivery of the fraction of inspired oxygen $\left(\mathrm{F}_{\mathrm{i}} \mathrm{O}_{2}\right)$. The basic differences between these methods are shown in table 1.

\section{THE USE OF HOME NONINVASIVE POSITIVE-PRESSURE VENTILATION IN COPD}

Noninvasive positive-pressure ventilation at home could have several possible benefits for the COPD patient. These benefits include the possibilities of improving the outcomes of patients hospitalized for acute exacerbations when discharged to home, preventing the need for readmission to the hospital post-discharge, and improving the daily functional status of patients suffering from chronic respiratory failure. A consensus conference published in 1999 concluded that COPD patients most likely to benefit from NPPV are those with a $\mathrm{PaCO}_{2}$ $\geq 55 \mathrm{~mm} \mathrm{Hg}(7.3 \mathrm{kPa})$ or those with a $\mathrm{PaCO}_{2}$ of $50-54 \mathrm{~mm} \mathrm{Hg}(6.7-7.2 \mathrm{kPa})$ that desaturated at night despite oxygen therapy or who had recurrent hospitalizations for hypercapnic respiratory failure ${ }^{22}$. These recommendations were made based on evidence that was "conflicting and far from definitive". In 2015 an official American
Thoracic Society/European Respiratory Society (ATS/ERS) statement for research questions in COPD was published ${ }^{23}$. They recommended that studies be done to assess the long-term effects of this NPPV in chronic respiratory failure, and to determine the characteristics of COPD patients most likely to benefit from NPPV. Seemingly little progress has been made over this time, and a large prospective randomized trial has yet to be conducted. Despite the lack of a definitive trial, smaller studies have helped to develop the role of NPPV in the management of hypercapnic respiratory failure due to COPD. Although improvements in blood gases and quality of life are important, a major goal for home NPPV is a reduction in acute COPD exacerbations that result in emergency room visits and hospitalizations.

Using NPPV to target the sequela of acute exacerbations of COPD and its aftermath has great importance in the care of the COPD patient. Acute exacerbations of chronic obstructive pulmonary disease (AECOPD) are to COPD what myocardial infarctions are to coronary artery disease; they are acute and sometimes deadly manifestations of a chronic disease. Hospitalized exacerbations are particularly relevant in COPD and profoundly impact patient survival, function, symptoms, and health status as well as costs. Acute acerbations of COPD account for $31-68 \%$ of the total costs of COPD care in the USA, and hospitalizations account for a significant component of these costs ${ }^{24}$. COPD is the third leading cause of re-hospitalization; re-hospitalization has a particularly negative impact on morbidity, mortality, and increased costs ${ }^{25}$. Although many pharmacologic and behavioural interventions have been used to prevent COPD exacerbations, it is not clear that any of these 


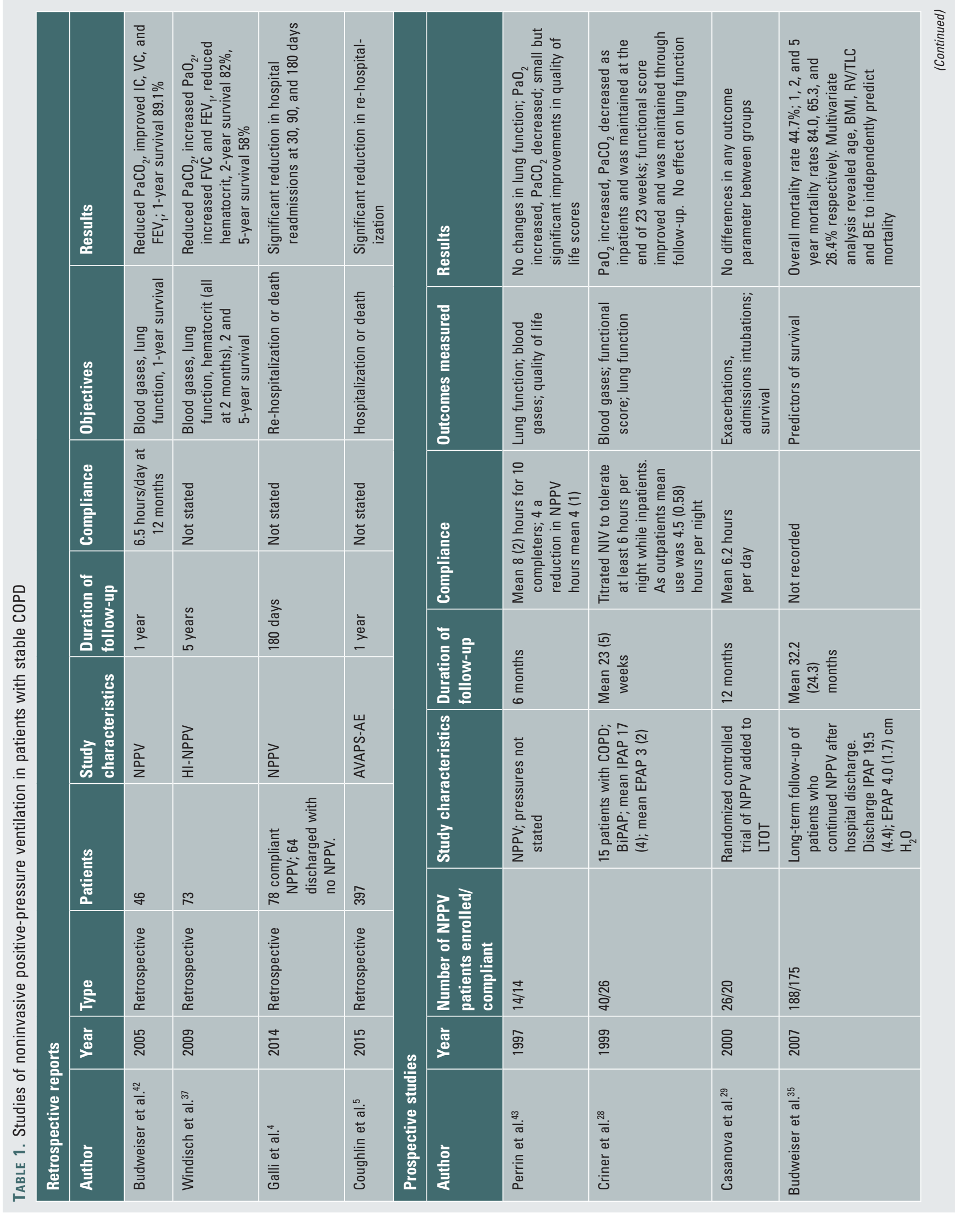




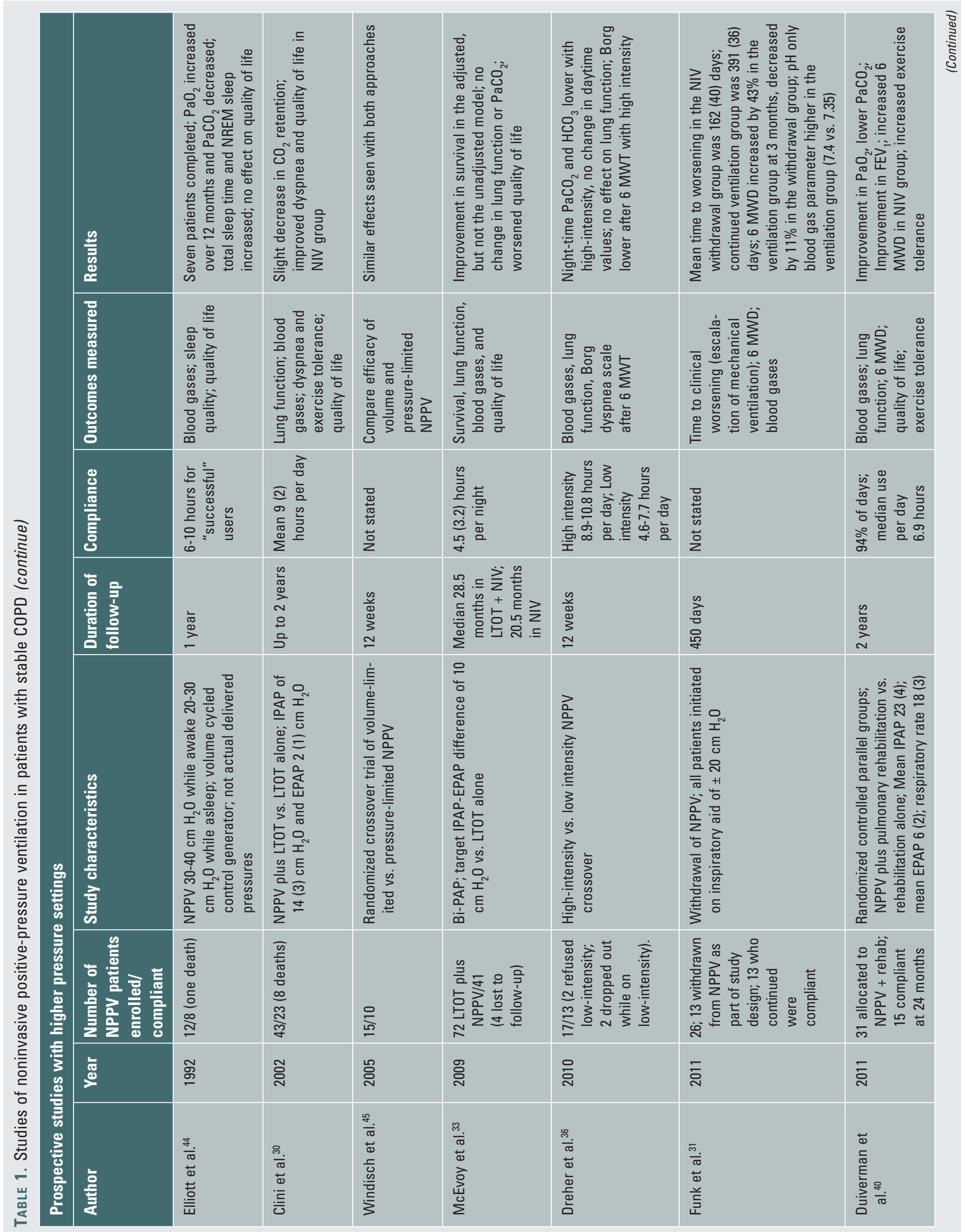




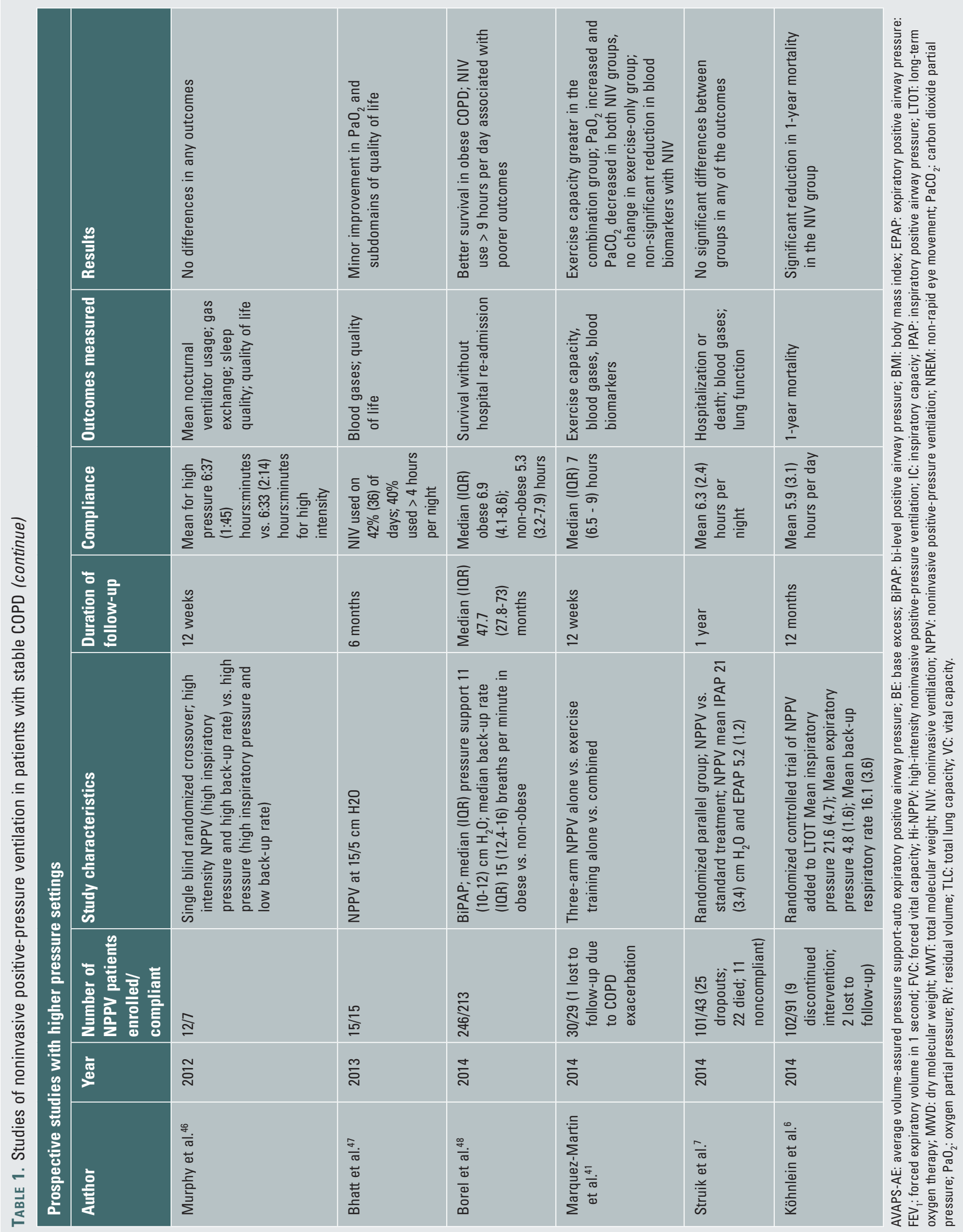


reduce re-hospitalization or mortality rates ${ }^{25}$. Respiratory failure during the initial COPD hospitalization is one factor well known to increase morbidity, mortality, and the need for re-hospitalization ${ }^{25}$.

A summary of current policy to use respiratory assist devices in severe COPD in the USA is as follows and limits the use of NPPV when trying to prescribe it to recently discharge patients with hypercapnic respiratory failure. To prescribe it, patients must demonstrate the following two criteria: (i) a $\mathrm{PaCO}_{2^{\prime}}$ done while awake and breathing, the patient's usual $\mathrm{FIO}_{2}$, is $\geq 52 \mathrm{~mm} \mathrm{Hg}$, and sleep oximetry demonstrates oxygen saturation $\leq 88 \%$ for at least five continuous minutes, done while breathing oxygen at 2 litres per minute or the patient's usual $\mathrm{FIO}_{2}$ (whichever is higher); and (ii) prior to initiating therapy, obstructive sleep apnoea (OSA), and treatment with a continuous positive airway pressure device (CPAP) has been considered and ruled out ${ }^{26}$. Adherence to the above guidelines restricts the use of NPPV in those hospitalized for severe AECOPD complicated by respiratory failure when transitioned home. For several decades investigators have posited that NPPV could improve ventilator muscle function, nocturnal and consequently daytime gas exchange, and sleep quality and duration in severe COPD. However, due to the conflicting results of the studies conducted to date, clear recommendations on NPPV use in this situation have been difficult to make. In 2013 a Cochrane report concluded that NPPV has "no clinically or statistically significant effect on gas exchange, exercise tolerance, quality of life, lung function, respiratory muscle strength or sleep efficiency (and) should only be used in the context of a clinical trial" 27 .
Important information has become available regarding the value of NPPV in improving outcomes in COPD patients with chronic respiratory failure and decreasing hospitalization readmission and improving survival. These data provide important information regarding the level of resting hypercapnia in selecting COPD patients that may benefit from NPPV, the benefits of higher inspiratory pressure settings with NPPV application, the importance of a backup respiratory rate, the utility and ease of use of intelligent volume assured auto-titrating pressure support devices, and lack of need to perform a sleep study or nocturnal five minute oxygen desaturation challenge to select patients who may improve with the use of chronic NPPV. This information is discussed below.

\section{STUDIES OF HOME NONINVASIVE POSITIVE-PRESSURE VENTILATION IN COPD}

Table 1 summarizes the retrospective and prospective studies that included patients with hypercapnic COPD. Criner et al. ${ }^{28}$ evaluated the acute and chronic effects of NPPV in patients with chronic respiratory failure related to COPD or restrictive ventilator disorders, and initiated NPPV in a noninvasive respiratory care unit and followed patients after discharge in a comprehensive outpatient program to maximize compliance with chronic NPPV therapy. They concluded, "Future studies, preferably conducted in a prospective, randomized, and controlled fashion, are required to determine the subgroups of COPD patients who may best benefit from NPPV therapy." Casanova et al. ${ }^{29}$ attempted to determine one-year efficacy of NPPV added to long-term oxygen therapy in severe COPD. They randomized 52 patients 
with severe COPD $\left(\mathrm{FEV}_{1}<45 \%\right)$ to NPPV plus standard care, or standard care alone, and reported no differences in mortality, number of acute exacerbations, or hospitalizations. Clini et al. ${ }^{30}$ studied 122 stable hypercapnic COPD patients on long-term oxygen therapy (LTOT) for at least six months. Ninety patients were randomly assigned to NPPV plus LTOT ( $n=43$ ) or to LTOT alone $(n=47)$. Lung function, inspiratory muscle function, exercise tolerance, and sleep quality score did not change over time in either group in follow-up over two years. By contrast, $\mathrm{PaCO}_{2}$ levels inspiring usual oxygen, resting dyspnoea, and health-related quality of life changed in favour of NPPV plus LTOT. Overall hospital admissions trended to decrease in the NPPV/LTOT (decreasing by 45\%) as compared with the LTOT group (increasing by 27\%). Several other studies have shown attenuation of clinical worsening, decreased hospitalizations, and trend to improved survival with NPPV compared to usual care ${ }^{31-33}$. As a result of the above data, current Medicare coverage policy for use of respiratory assist devices to treat chronic respiratory failure in COPD stem from a National Association for Medical Direction of Respiratory Care (NAMDRC) consensus conference in 1998 and a Centers for Medicare and Medicaid Services (CMS) anal$y$ sis of the use of respiratory assist devices in COPD from the above data ${ }^{22}$. Galli et al. ${ }^{4}$ recently published a retrospective, single-centre chart review on patients hospitalized in 2011 with a diagnosis of AECOPD and hypercapnia who used NPPV during hospitalization at a single large urban academic medical centre. One hundred and sixty-six patients were included and were divided into two groups: patients who used NPPV post-discharge and patients who did not. Patients who used NPPV post-discharge were comparable to those who did not in terms of severe airflow obstruction, comorbid conditions, and discharge medications. Patients who used NPPV at discharge tended to be of higher body mass index (BMI) and have a greater prevalence of OSA and obesity hypoventilation syndrome (OHS) in addition to severe COPD. Patients in the home NPPV post-discharge group demonstrated superior event-free survival compared to the non-NPPV post-discharge group $\left(\chi^{2}=23.8\right.$; $\mathrm{p}<0.0001$ ) (Fig. 1). The home NPPV post-discharge group had a statistically significant reduction in hospital readmissions (40 vs. 75\%; $\mathrm{p}<0.0001$ ) through 180 days from the index admission. A multivariate analysis was performed using a Cox regression model to identify baseline characteristics associated with reduced event-free survival. No home NPPV at discharge, home oxygen use, long-acting $\beta 2$-agonist use, and pulmonary hypertension were variables associated with reduced eventfree survival. The two study groups were subsequently matched with the use of propensity scores. Propensity scores for group matching were calculated using the variables of age, $\mathrm{BMI}, \mathrm{FEV}_{1}$, OSA/OHS, $\mathrm{PaCO}_{2}$ at discharge, home oxygen, and admission date. The matching process resulted in 74 patients from the NPPV post-discharge group being statistically matched with 74 patients from the non-NPPV post-discharge group. Subjects who did not use NPPV post-discharge had inferior event-free survival through 180 days after statistical matching compared to patients who used NPPV post-discharge (HR: 3.33; 95\% CI: 2.07-5.34; $\mathrm{p}<0.0001)$.

Another retrospective study of a quality improvement program performed at a single centre used a multifaceted intervention that 


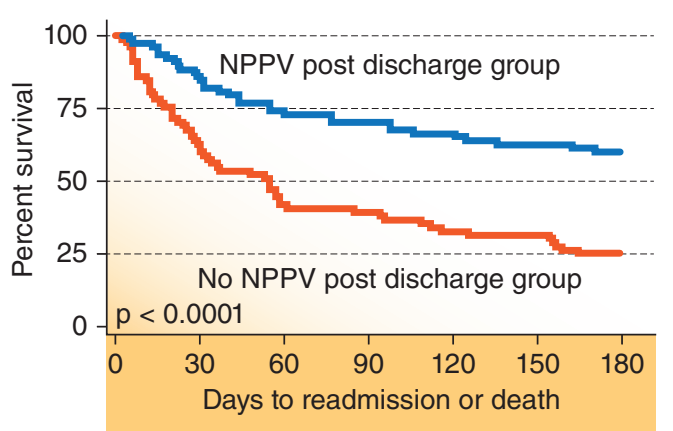

Figure 1. Kaplan Meier curve of event-free survival comparing patients who used noninvasive positive-pressure ventilation post-discharge versus patients who did not use noninvasive positive-pressure ventilation post-discharge (reproduced with permission from Galli JA et al. ${ }^{4}$.

NPPV: noninvasive positive-pressure ventilation.

included nocturnal administration of an advanced form of NPPV average volume-assured pressure support-auto expiratory positive airway pressure (AVAPS-AE) initiated by a respiratory therapist, with medication reconciliation by a pharmacist, adequate provision of oxygen and on-going respiratory therapist-led care in patients who had been hospitalized twice in the preceding year with an acute COPD exacerbation ${ }^{5}$. All patients were placed on AVAPS-AE, a bi-level positive airway pressure modality that can automatically titrate expiratory positive airway pressure (EPAP) to treat obstructive events if obstructive sleep apnoea is present, and automatically adjust inspiratory positive airway pressure (IPAP) to achieve a physician-defined target tidal volume based on ideal body weight set at 5-7 ml/kg. Settings were chosen to maximize expiratory time to help to avoid breath stacking by adjusting the backup rate setting on the patient's spontaneous rate.
The device was set with a range from a minimum of $5 \mathrm{~cm} \mathrm{H}_{2} \mathrm{O}$ (EPAP min) to maximum of $15 \mathrm{~cm} \mathrm{H}_{2} \mathrm{O}$ (EPAP max); inspiratory pressure support ranged from a minimum of $2 \mathrm{~cm}$ $\mathrm{H}_{2} \mathrm{O}$ (pressure support minimum) to a maximum of $26 \mathrm{~cm} \mathrm{H}_{2} \mathrm{O}$ (pressure support maximum); automatic backup rate and fractional concentration of entrained supplemental oxygen were based upon wakefulness determination of supplemental oxygen needs. The use of intelligent auto-titrating volume assured pressure support devices has been recently reported to improve compliance and adherence with NPPV daily use ${ }^{34}$. Three hundred and ninety-seven consecutive patients were eligible for the trial because they had $\geq$ 2 hospitalizations in the past year. The proportion of patients who were readmitted $\geq 2$ occasions decreased from $100 \%$ in the year prior to the intervention to $2.2 \%$ in the following year $(\mathrm{p}<0.0001)$. The above data, although retrospective, demonstrate that following hospitalization for AECOPD complicated by hypercapnic respiratory failure, patients who used home NPPV post-discharge on a daily basis had lower readmission rates and improved event-free survival. Moreover, this group, although severely obstructed, had higher BMI and greater prevalence of comorbid OSA and obesity hypoventilation. Although the data are retrospective, they reflect a current "real world" clinical use of NPPV in patients with severe COPD exacerbation who are hospitalized, and highlights the importance of continuing NPPV therapy as an outpatient immediately post-discharge on a daily basis.

In contrast to the above data, a study by Struik et al. ${ }^{7}$ examined outcomes in severe COPD patients discharged after an admission for 


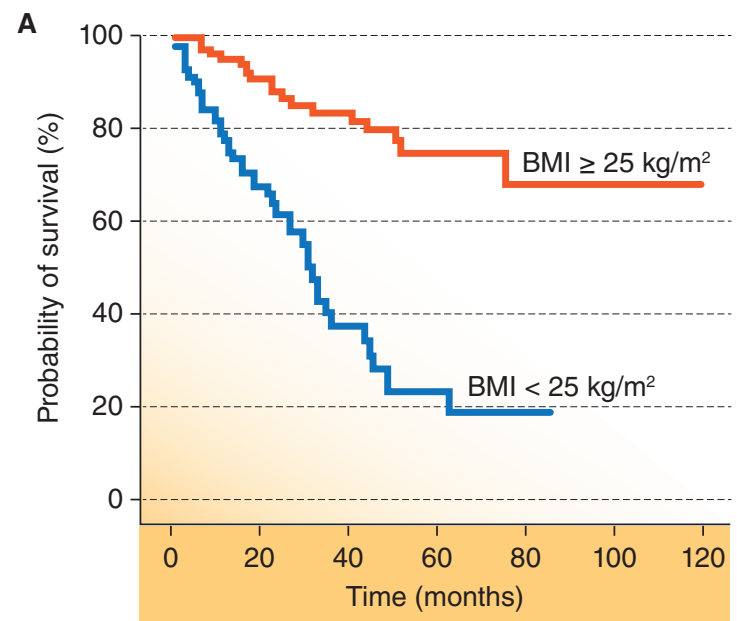

B

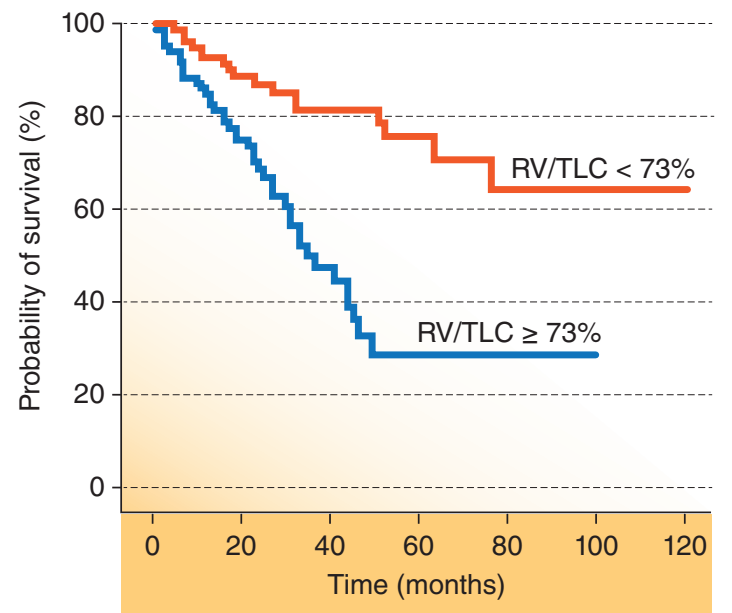

C

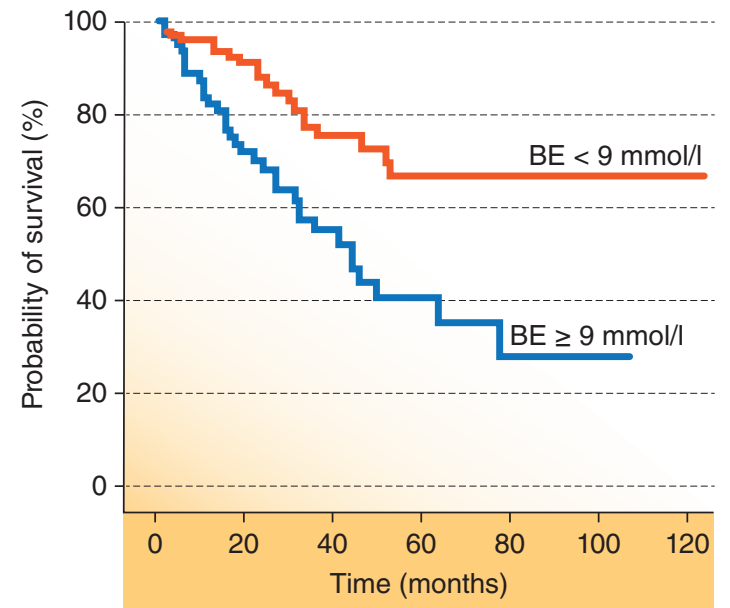

FIgUrE 2. Predictors of survival in COPD patients receiving home noninvasive positive-pressure ventilation (reproduced with permission from Struik FM et al. ${ }^{7}$.

BE: base excess; BMI: body mass index; RV: residual volume; TLC: total lung capacity.

hypercapnic respiratory failure (all required NPPV except $12 \%$ of control patients and $13 \%$ of NPPV users who were intubated). This year-long, randomized controlled trial allocated 101 patients to continue NPPV after hospitalization and 100 patients to standard care including long term oxygen. At baseline, patients had GOLD Stage 3 or 4, mean age 64 years, BMI $25 \mathrm{~kg} / \mathrm{m}^{2}, \mathrm{FEV}_{1} 26 \%$ and $\mathrm{PaCO}_{2}$ 55-60 $\mathrm{mm} \mathrm{Hg}$ with no significant differences between the NPPV and control groups (Fig. 2). The authors did not assess for OSA. The NPPV patients were treated for a year with average IPAP $21 \mathrm{~cm} \mathrm{H}_{2} \mathrm{O}$, EPAP $5 \mathrm{~cm} \mathrm{H}_{2} \mathrm{O}$ and 
backup rate 16; average NPPV utilization among the 54 completers was 6.9 hours nocturnally. There were no significant differences in readmissions, mortality (22 in each group), or blood gases, but there was a trend for better quality of life in the NPPV group. The authors concluded that NPPV did not reduce re-hospitalization or mortality rates following COPD hospitalization with respiratory failure, but that the trend toward better health-related quality of life deserved further study. These recent studies report contradictory findings, but a major difference between the studies may be the prevalence of OSA/OHS that was substantially higher in the Galli study. The combination of OSA and COPD, referred to as the "overlap syndrome", may identify COPD patients particularly likely to benefit from home NPPV.

Budweiser et al. ${ }^{35}$ also reported the independent effect of greater BMI on improving survival in obese COPD patients treated with home NPPV. They also identified higher base excess and less gas trapping as additional factors identifying patients with better outcomes when using NPPV (Fig. 3). Hence, patients with COPD and obesity, the overlap syndrome, may be a subgroup that has a greater degree of hypoventilation and less airways obstruction and may beneficially respond to NPPV. This speculation needs to be supported by prospective randomized investigation.

\section{HIGH-INTENSITY NONINVASIVE POSITIVE-PRESSURE VENTILATION}

Some studies suggest that night time NPPV employing higher inspiratory and expiratory

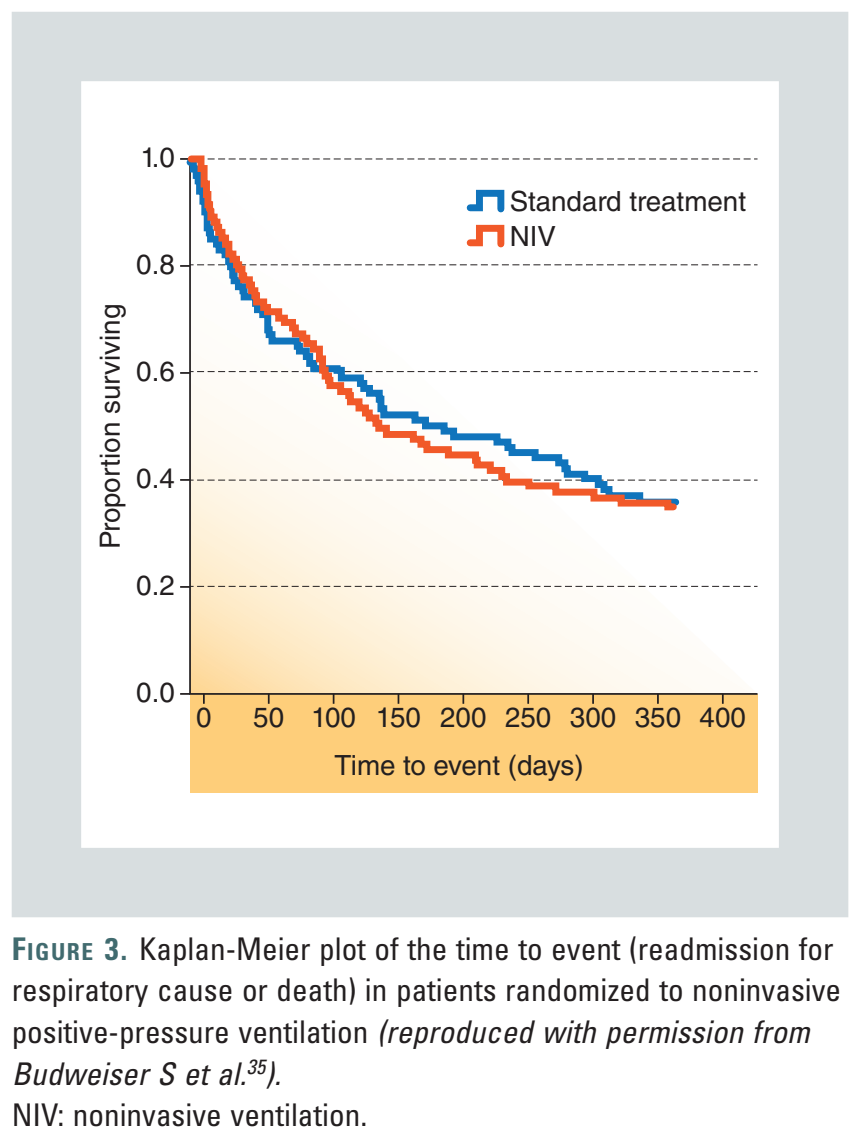

pressures with a minimum backup respiratory rate might increase the effectiveness of this therapy ${ }^{36,37}$. The rationale for this is that the higher inspiratory pressure leads to recruitment of airways that would otherwise not be ventilated, and higher expiratory pressure prevents early closure of the alveoli and enhances ventilation. Using a minimum respiratory backup rate assures that respirations are initiated independently of the respiratory centre, which may no longer be sensitive to low levels of oxygen or high levels of carbon dioxide in the bloodstream. Night time ventilation in this context can reset the respiratory centre sensitivity, which results in improvement in blood gases during the daytime even when noninvasive ventilation is not being used. In contrast to low-intensity NPPV, high-intensity NPPV has been associated with reductions in 
cardiac output, which may be a concern in patients with underlying heart disease ${ }^{38}$.

Köhnlein et al. ${ }^{6}$ recently published the results of a prospective, multicenter, randomized controlled trial of NPPV in patients with chronic stable hypercapnic COPD. Patients were GOLD stage IV COPD with resting $\mathrm{PaCO}_{2} \geq 51.9 \mathrm{mmHg}$ and $\mathrm{pH}>7.35$. Patients were comparable between the groups. NPPV was targeted to reduce baseline $\mathrm{PaCO}_{2}$ by $\geq$ $20 \%$ to achieve $\mathrm{PaCO}_{2}$ values $<48.1 \mathrm{mmHg}$. A pre-set pressure mode was used with a high backup rate (18-22 breath per minute). The mean inspiratory pressure was $21.6 \mathrm{~cm}$ $\mathrm{H}_{2} \mathrm{O}$, mean expiratory pressure was $4.8 \mathrm{~cm}$ $\mathrm{H}_{2} \mathrm{O}$, and mean backup rate was $16.1 \mathrm{bpm}$ (range 2-24). Seventy patients (69\%) had backup rates of $14.1 \mathrm{bpm}$. Mean NPPV usage was 5.6 hours per day. The primary outcome was one-year all-cause mortality; one-year mortality was $12 \%$ in the NPPV group and $33 \%$ in the control group (Fig. 4). Secondary improvements were also seen in $\mathrm{FEV}_{1}, \mathrm{PaCO}_{2}$ and $\mathrm{pH}$ in the NPPV compared to control group. No intervention-related complications were reported except for facial skin rash in $14 \%$ of patients. These data showed a positive effect of NPPV on overall survival in patients with chronic hypercapnic COPD. This benefit was stable over one year and continued to show a durable effect.

This study differed from prior studies in chronic stable hypercapnic COPD by using a different technique to apply NPPV, high intensity NPPV (Hi-NPPV). The Hi-NPPV was targeted to reduce $\mathrm{PaCO}_{2} \geq 20 \%$ by using higher inflation pressures with a set backup rate. Hi-NPPV refers to higher levels of inspiratory pressure and higher backup

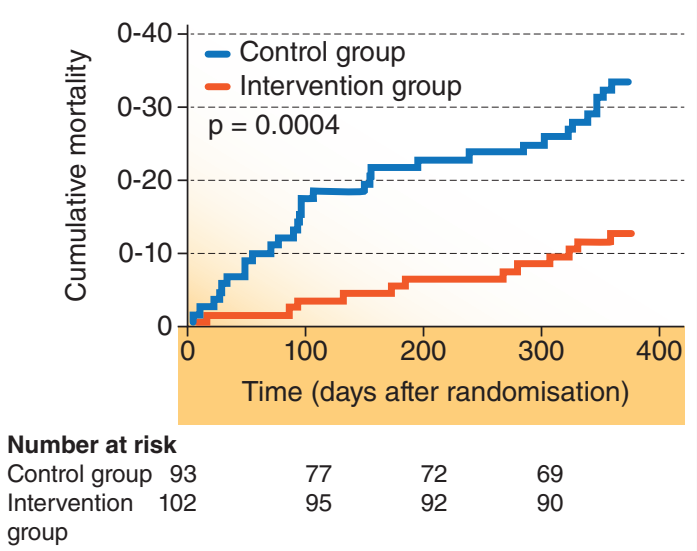

Figure 4. Effect of noninvasive positive-pressure ventilation with backup rate on survival in stable severe hypercapnic COPD. (reproduced with permission from Köhnlein $T$ et al. ${ }^{6}$ ).

rates to capture central drive and more effectively rest and control ventilation: inspiration times $0.5-5$ seconds, pressure trigger -2 to $+8 \mathrm{~cm} \mathrm{H}_{2} \mathrm{O}$, IPAP of $6-40 \mathrm{~cm} \mathrm{H}_{2} \mathrm{O}$, and respiratory rates (RR) 6-40 breaths/minute. The goal of Hi-NPPV is to achieve normocapnia and control ventilation. Dreher et al. ${ }^{36}$ originally reported that subjects using Hi-NPPV compared to lower conventional NPPV settings had higher expired tidal volumes, greater daily use (> 3.6 hours/day), more reductions in dyspnoea, and improvements in severe respiratory insufficiency questionnaire.

A very recent report highlights the need for more study of chronic nocturnal domiciliary use of noninvasive ventilation to treat patients with chronic underlying cardiopulmonary conditions. Cowie et al. ${ }^{39}$ randomly assigned 1,325 patients with the left ventricular ejection fraction $\leq 45 \%$, an apnoea hypopnea index $\geq 15$ events/hour, and predominance of 
central events to receive guideline-based care with chronic nocturnal adaptive servo-ventilation. The primary endpoint in the time to event analysis was the composite index of all-cause death, need for life-saving cardiovascular intervention resuscitation after setting cardiac arrest, or unplanned hospitalization for worsening heart failure. The incidence of the primary endpoint did not differ significantly between the adaptive servo-ventilation group and the control group; however, all-cause mortality and cardiovascular mortality were significantly higher in the adaptive servo-ventilation group than in the control group. These results were seen despite effective control of central sleep apnoea during adaptive servo-ventilation. The reasons for the above findings are not known, but one possibility may be that the application of positive-pressure ventilation may impair cardiac function in some patients with severe heart failure. As a result, we believe it is prudent to avoid the use of NPPV in patients with COPD and known ejection fraction $\leq 45 \%$ until the reasons for the increased all-cause and cardiovascular mortality are evident in this subgroup.

COPD patients suffer from significant comorbid conditions (e.g., congestive heart failure, coronary artery disease, osteoporosis, diabetes mellitus, obesity) that adversely alter their outcome, deconditioning, and weakness are musculoskeletal comorbidities found in COPD. Two studies have studied the effects of NPPV when added to pulmonary rehabilitation programs. Duiverman et al. ${ }^{40}$ examined the effects of home-based high-intensity NPPV added to pulmonary rehabilitation in a two-year randomized trial. Improvements were noted in health-related quality of life, gas exchange, and exercise tolerance. The improvements in these parameters appeared to increase with time. Improved exercise capacity was noted by Marquez-Martin et al. ${ }^{41}$ in a 12-week trial in patients who received NPPV in addition to exercise. These data highlight that combined therapy with rehabilitation as well as augmenting ventilation may be important to maximize any benefit seen with NPPV in deconditioned and weak COPD patients with underlying chronic respiratory failure.

\section{CONCLUSIONS}

Although NPPV is the predominate ventilatory mode used to treat COPD patients who are hospitalized with acute respiratory failure, the role of home NPPV in the management of severe but stable hypercapnic respiratory failure remains unclear. From available data, it appears that a subgroup of patients may benefit from this therapy: those with COPD who are more obese, less gas trapped with recent acute-on-chronic respiratory failure. The optimal subject characteristics (e.g., lung function, BMI, clinical history, and gas exchange parameters), however, remain undefined at present. Moreover the optimal outpatient NPPV treatment regime (pressure settings, use of a backup rate, hours of use) to maximize benefit or compliance also remains undefined. Although NPPV at home may have an important role in the treatment of severe but stable hypercapnic COPD patients, prospective randomized controlled trials of sufficient power to identify the patient characteristics most likely to benefit are needed. 


\section{REFERENCES}

1. Elliott MW, Nava S. Noninvasive ventilation for acute exacerbations of chronic obstructive pulmonary disease: "Don't think twice, it's alright!". Am J Respir Crit Care Med. 2012;185:121-3.

2. Chandra D, Stamm JA, Taylor B et al. Outcomes of noninvasive ventilation for acute exacerbations of chronic obstructive pulmonary disease in the United States, 1998-2008. Am J Respir Crit Care Med. 2012;185:152-9.

3. Lindenauer PK, Stefan MS, Shieh MS, Pekow PS, Rothberg MB, Hill NS. Outcomes associated with invasive and noninvasive ventilation among patients hospitalized with exacerbations of chronic obstructive pulmonary disease. JAMA Intern Med. 2014;174:1982-93.

4. Galli JA, Krahnke JS, James Mamary A, Shenoy K, Zhao H, Criner GJ. Home non-invasive ventilation use following acute hypercapnic respiratory failure in COPD. Respir Med. 2014;108:722-8.

5. Coughlin S, Liang WE, Parthasarathy S. Retrospective assessment of home ventilation to reduce rehospitalization in chronic obstructive pulmonary disease. J Clin Sleep Med. 2015;11:663-70.

6. Köhnlein T, Windisch W, Kohler D et al. Non-invasive positive pressure ventilation for the treatment of severe stable chronic obstructive pulmonary disease: a prospective, multicentre, randomised, controlled clinical trial. Lancet Respir Med. 2014;2:698-705.

7. Struik FM, Sprooten RT, Kerstjens HA et al. Nocturnal non-invasive ventilation in COPD patients with prolonged hypercapnia after ventilatory support for acute respiratory failure: a randomised, controlled, parallel-group study. Thorax. 2014;69:826-34.

8. White DP, Criner GJ, Dreher M et al. The role of noninvasive ventilation in the management and mitigation of exacerbations and hospital admissions/ readmissions for the patient with moderate to severe COPD (multimedia activity). Chest. 2015;147:1704-5.

9. Belda FJ, Soro M, Ferrando C. Pathophysiology of respiratory failure. Trends in Anaesthesia and Critical Care Medicine. 2013;3:265.

10. Officer TM, Pellegrino R, Brusasco V, Rodarte JR. Measurement of pulmonary resistance and dynamic compliance with airway obstruction. J Appl Physiol. 1998;85:1982-8.

11. Purro A, Appendini L, Polillo C et al. Mechanical determinants of early acute ventilatory failure in COPD patients: a physiologic study. Intensive Care Med. 2009;35:639-47.

12. Jubran A, Tobin MJ. Pathophysiologic basis of acute respiratory distress in patients who fail a trial of weaning from mechanical ventilation. Am J Respir Crit Care Med. 1997;155:906-15.

13. Rodriguez-Roisin R, Drakulovic M, Rodriguez DA, Roca J, Barbera JA, Wagner PD. Ventilation-perfusion imbalance and chronic obstructive pulmonary disease staging severity. J Appl Physiol. 2009;106:1902-8.

14. Kawagoe Y, Permutt S, Fessler HE. Hyperinflation with intrinsic PEEP and respiratory muscle blood flow. J Appl Physiol. 1994;77:2440-8.

15. Marini JJ. Dynamic hyperinflation and auto-positive end-expiratory pressure: lessons learned over 30 years. Am J Respir Crit Care Med. 2011;184:756-62.

16. Ottenheijm CA, Heunks LM, Dekhuijzen RP. Diaphragm adaptations in patients with COPD. Respir Res. 2008;9:12.

17. Orozco-Levi M. Structure and function of the respiratory muscles in patients with COPD: impairment or adaptation? Eur Respir J Suppl. 2003;46:41-51s.

18. Tobin MJ, Laghi F, Brochard L. Role of the respiratory muscles in acute respiratory failure of COPD: lessons from weaning failure. J Appl Physiol. 2009;107:962-70.

19. Diaz O, Iglesia R, Ferrer $M$ et al. Effects of noninvasive ventilation on pulmonary gas exchange and hemodynamics during acute hypercapnic exacerbations of chronic obstructive pulmonary disease. Am J Respir Crit Care Med. 1997;156:1840-5.
20. Fessler HE, Brower RG, Wise RA, Permutt S. Mechanism of reduced LV afterload by systolic and diastolic positive pleural pressure. J Appl Physiol. 1988;65:1244-50.

21. Shapiro SH, Ernst P, Gray-Donald K et al. Effect of negative pressure ventilation in severe chronic obstructive pulmonary disease. Lancet. 1992; 340:1425-9.

22. Clinical indications for noninvasive positive pressure ventilation in chronic respiratory failure due to restrictive lung disease, COPD, and nocturnal hypoventilation--a consensus conference report. Chest. 1999; 116:521-34.

23. Celli BR, Decramer M, Wedzicha JA et al. ATS/ERS Task Force for COPD Research. An official American Thoracic Society/European Respiratory Society statement: research questions in COPD. Eur Respir J 2015;45:879-905

24. Strassels SA, Smith DH, Sullivan SD, Mahajan PS. The costs of treating COPD in the United States. Chest. 2001;119:344-52.

25. Marchetti N, Criner GJ, Albert RK. Preventing acute exacerbations and hospital admissions in COPD. Chest. 2013;143:1444-54.

26. CMS. Decision memo for noninvasive positive pressure ventilation for RADs in COPD (CAG-00052N). 2014 (October 5). Available at: http:/ / www.cms.gov/medicare-coverage-database/details/nca-decision-memo. aspx? $\mathrm{NCAId}=56 \&$ ver $=5 \&$ viewAMA $=\mathrm{Y} \& \mathrm{bc}=\mathrm{AAAAAAAAEAAA} \&$

27. Struik FM, Lacasse Y, Goldstein R, Kerstjens HM, Wijkstra PJ. Nocturnal non-invasive positive pressure ventilation for stable chronic obstructive pulmonary disease. Cochrane Database Syst Rev. 2013;6:CD002878.

28. Criner GJ, Brennan K, Travaline JM, Kreimer D. Efficacy and compliance with noninvasive positive pressure ventilation in patients with chronic respiratory failure. Chest. 1999;116:667-75.

29. Casanova C, Celli BR, Tost L et al. Long-term controlled trial of nocturna nasal positive pressure ventilation in patients with severe COPD. Chest 2000;118:1582-90.

30. Clini E, Sturani C, Rossi A et al. Rehabilitation and Chronic Care Study Group, Italian Association of Hospital Pulmonologists (AIPO). The Italian multicentre study on noninvasive ventilation in chronic obstructive pulmonary disease patients. Eur Respir J. 2002;20:529-38.

31. Funk GC, Breyer MK, Burghuber OC et al. Long-term non-invasive ventilation in COPD after acute-on-chronic respiratory failure. Respir Med. 2011;105:427-34.

32. Cheung AP, Chan VL, Liong JT et al. A pilot trial of non-invasive home ventilation after acidotic respiratory failure in chronic obstructive pulmonary disease. Int J Tuberc Lung Dis. 2010;14:642-9.

33. McEvoy RD, Pierce RJ, Hillman D et al. Australian trial of non-invasive Ventilation in Chronic Airflow Limitation (AVCAL) Study Group. Nocturnal non-invasive nasal ventilation in stable hypercapnic COPD: a ran domised controlled trial. Thorax. 2009;64:561-6.

34. Kelly JL, Jaye J, Pickersgill RE, Chatwin M, Morrell MJ, Simonds AK. Randomized trial of 'intelligent' autotitrating ventilation versus standard pressure support non-invasive ventilation: Impact on adherence and physiological outcomes. Respirology. 2014;19:596-603.

35. Budweiser S, Jorres RA, Riedl T et al. Predictors of survival in COPD patients with chronic hypercapnic respiratory failure receiving noninvasive home ventilation. Chest. 2007;131:1650-8.

36. Dreher M, Storre JH, Schmoor C, Windisch W. High-intensity versus low-intensity non-invasive ventilation in patients with stable hypercapnic COPD: a randomised crossover trial. Thorax. 2010;65:303-8.

37. Windisch W, Haenel M, Storre JH, Dreher M. High-intensity non-invasive positive pressure ventilation for stable hypercapnic COPD. Int J Med Sci. 2009;6:72-6.

38. Lukacsovits J, Carlucci A, Hill N et al. Physiological changes during lowand high-intensity noninvasive ventilation. Eur Respir J. 2012;39:869-75. 
39. Cowie MR, Woehrle H, Wegscheider $\mathrm{K}$ et al. Adaptive servo-ventilation for central sleep apnea in systolic heart failure. N Engl J Med. 2015; 373:1095-105.

40. Duiverman ML, Wempe JB, Bladder G et al. Two-year home-based nocturnal noninvasive ventilation added to rehabilitation in chronic obstructive pulmonary disease patients: a randomized controlled trial. Respir Res. 2011;12:112.

41. Marquez-Martin E, Ruiz FO, Ramos PC, Lopez-Campos JL, Azcona BV, Cortes EB. Randomized trial of non-invasive ventilation combined with exercise training in patients with chronic hypercapnic failure due to chronic obstructive pulmonary disease. Respir Med. 2014;108:1741-51.

42. Budweiser S, Heinemann F, Fischer W, Dobroschke J, Pfeifer M. Long-term reduction of hyperinflation in stable COPD by non-invasive nocturnal home ventilation. Respir Med. 2005;99:976-84.

43. Perrin C, El Far Y, Vandenbos F et al. Domiciliary nasal intermittent positive pressure ventilation in severe COPD: effects on lung function and quality of life. Eur Respir J. 1997;10:2835-9.
44. Elliott MW, Simonds AK, Carroll MP, Wedzicha JA, Branthwaite MA. Domiciliary nocturnal nasal intermittent positive pressure ventilation in hypercapnic respiratory failure due to chronic obstructive lung disease: effects on sleep and quality of life. Thorax. 1992;47:342-8.

45. Windisch W, Storre JH, Sorichter S, Virchow JC. Comparison of volumeand pressure-limited NPPV at night: a prospective randomized cross-over trial. Respir Med. 2005;99:52-9.

46. Murphy PB, Brignall K, Moxham J, Polkey MI, Davidson AC, Hart N. High pressure versus high intensity noninvasive ventilation in stable hypercapnic chronic obstructive pulmonary disease: a randomized crossover trial. Int J Chron Obstruct Pulmon Dis. 2012;7:811-18.

47. Bhatt SP, Peterson MW, Wilson JS, Durairaj L. Noninvasive positive pressure ventilation in subjects with stable COPD: a randomized trial. Int J Chron Obstruct Pulmon Dis. 2013;8:581-9.

48. Borel JC, Pepin JL, Pison C et al. Long-term adherence with non-invasive ventilation improves prognosis in obese COPD patients. Respirology. 2014;19:857-65. 